\title{
An Evaluation System Model for Analyzing Employee Turnover Risk
}

\author{
Xin Wang \\ School of Economics \& Management, Dalian Maritime University, Dalian 116026, \\ Liaoning, P.R. China wonderxin@sohu.com
}

\begin{abstract}
Evaluation system model is a key point of employee turnover risk evaluation in enterprises. It is important to the validity and veracity of evaluation result. This paper focused on the analysis and design of processes, and techniques of employee turnover risk evaluation system model. A multilevel employee turnover risk evaluation system model based on analyzing the influencing factors of employee turnover risk was put forward in the end, and it is a useful model in enterprise systems.
\end{abstract}

Keywords: Evaluation system model, Enterprise system, Employee turnover, Risk factors, Case -based reasoning, Knowledge management, Enterprise application, Relation database, Data warehousing, Human resource management

\section{INTRODUCTION}

In the times of knowledge economy, the competency among enterprises is the competency on human resources in the final analysis [1]. The employee turnover in enterprises is bound to lead labor cost, serious loss of intangible assets, and at the same time would weaken cohesiveness and personnel moral, it has great influence on enterprises competency power [2]. Thus, enterprises must find the employee turnover risk factors in time, to build scientific employee turnover risk evaluation system model, to evaluate the risk factors accurately, and to set up corresponding management strategies [3].

Employee turnover risk evaluation is to evaluate the risk factors, and to make clear the employee turnover risk factors system designing, the influence level and important grade of each factor [4]. Employee turnover risk evaluation aims at providing a basis for effective employee turnover risk management in enterprises. It is not only in the service of making enterprises' strategies and their application, but also contributes a lot in human resource management and enterprise culture building [5].

Please use the following format when citing this chapter:

Wang, X., 2007, in IFIP International Federation for Information Processing, Volume 255, Research and Practical Issues of Enterprise Information Systems Il Volume 2, eds. L. Xu, Tjoa A., Chaudhry S. (Boston: Springer), pp. 1127-1133. 


\section{EMPLOYEE TURNOVER RISK EVALUATION SYSTEM MODEL ANALYZING}

\subsection{Environmental Factors of Evaluation System Model}

- Employee turnover risk factors mainly come from outside enterprise conditions, inside enterprise conditions and employee conditions [7] (See Figure 1).

- Environmental factors of employee turnover are as follows:

- Enterprise External Conditions, mainly include employee supply \& demand conditions, industry conditions, and enterprise location conditions.

- Enterprise Internal Conditions, mainly include enterprise comprehensive strength level, salary and incentive systems, corporate culture, and employee socialization.

- Employee Conditions, mainly include age, gender, education, post, skill level, family situation, and values, personality characteristics, state of health, personal quality, evaluation of enterprise, job satisfaction, personal ideal.

- Outside enterprise conditions are the factors related to State economy development, systems designing, policies, laws and regulations. These conditions act on enterprise development and management directly, and have leading effective on employee idea of choosing jobs, personnel ideal [8]. At the same time, inside enterprise conditions and employee conditions act and affect on each other.

Employee turnover risk evaluation system model should meet the need of evaluating the risk of employee turnover, to carry out the overall evaluation on employee turnover risk from a multi-layer viewpoint. By analyzing the outside enterprise conditions, inside enterprise conditions and employee conditions comprehensively, a hierarchical model of analyzing employee turnover influencing factors was constructed.

\subsection{Hierarchy Analysis on Evaluation System Model}

Employee turnover risk evaluation system model divides the risk factors into groups, take each group for one level, it has four levels all together (See Figure 2):

The highest level of employee turnover risk evaluation system model was named as the integrated index level; it expresses the situation of employee turnover risk in enterprises. It presented the comprehensive effect of all the indexes.

The second level was macro-index level; it divided the target information into evaluation index collection. The macro-index has three types: outside enterprise index, inside enterprise index and employee index.

The third level was micro-index level, it is the dissolution and more detailed macro-index.

The fourth level was enterprise cases level, it means the different estimation of each level index of employee turnover risk factors in accordance with each 
enterprise's specific situations.

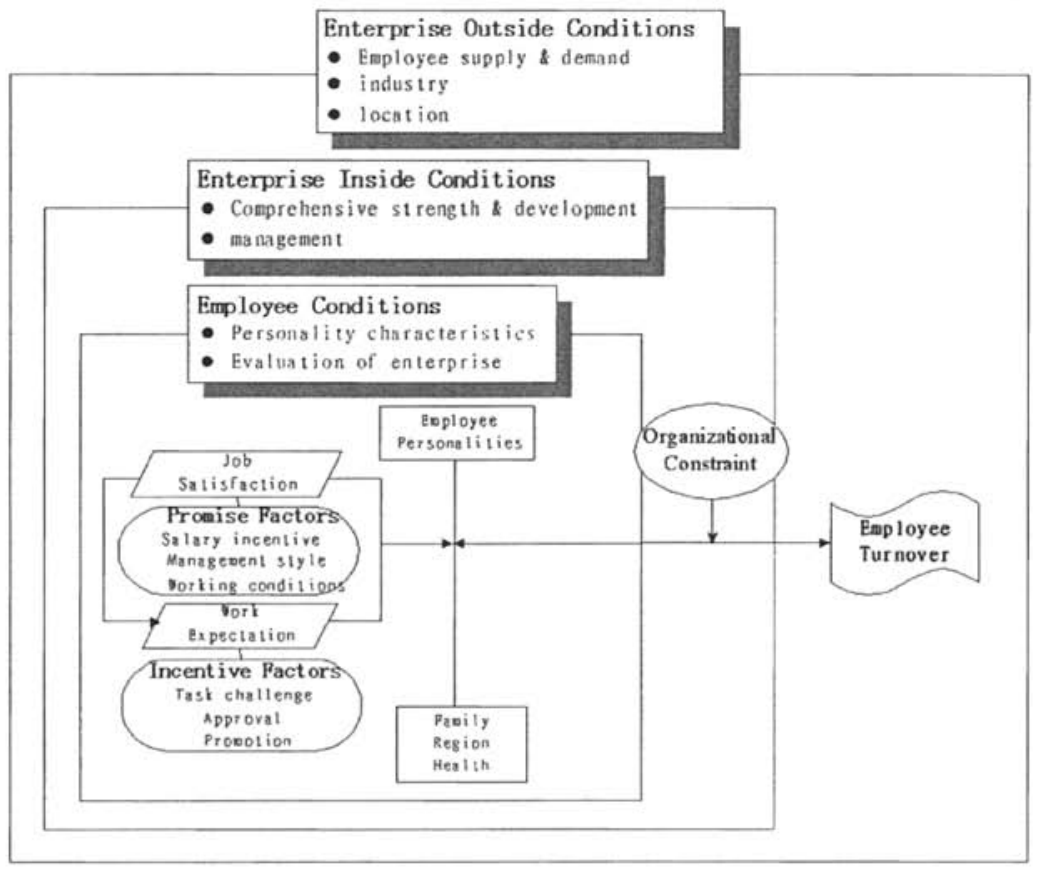

Figure 1. Environmental Factors of Employee Turnover

According to the above analysis, employee turnover risk evaluation system model can turn the qualitative description of employee turnover risk information into hierarchical structure, which has obvious level and easy to deal with. Thus we can act the evaluation on employee turnover risk with a well-defined objective in mind.

\section{EMPLOYEE TURNOVER RISK EVALUATION SYSTEM MODEL DESIGNING}

In order to design the employee turnover risk evaluation system model scientifically and effectively, we divided the designing process into two parts: the configuration stage and confirmation stage of evaluation system model (See Figure 3). 


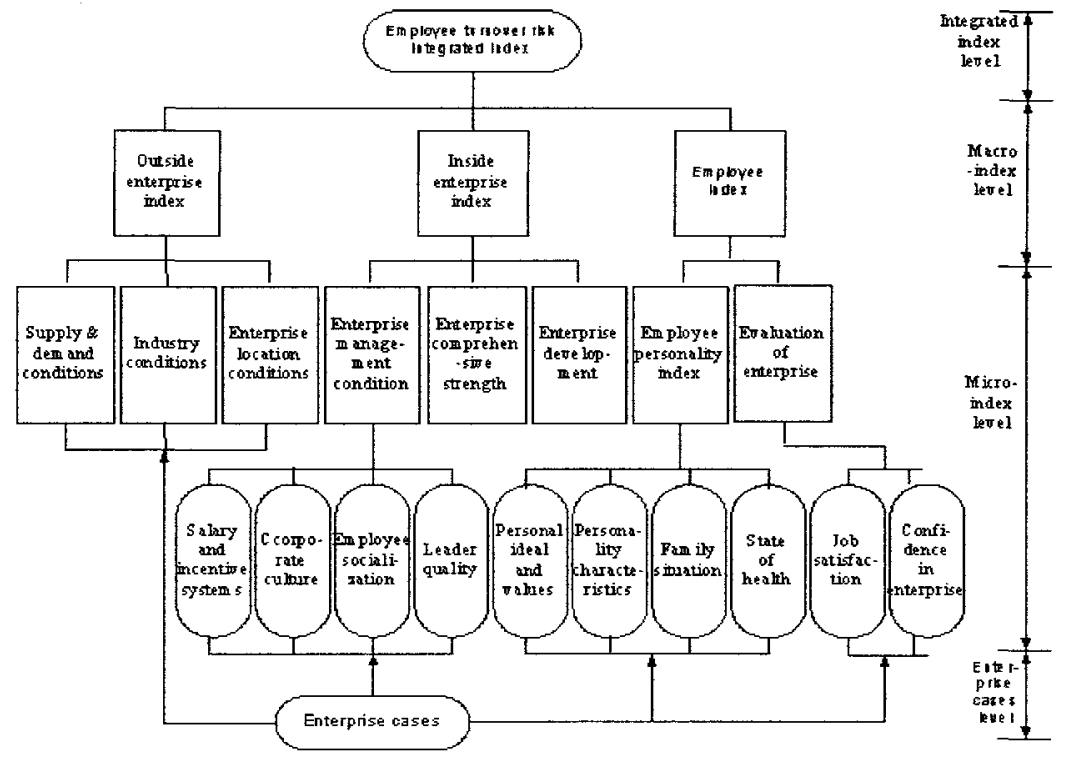

Figure 2. Employee Turnover Risk Evaluation System Model

\subsection{Configuration Stage of Evaluation System Model}

The configuration stage was used to make sure the specific designing, hierarchy relations and related properties of the risk factors in the model. Many methods may be used in this stage, such as analysis tools method, reality research method, case-based reasoning method and manual configuration method.

- Analysis tools method uses maturity analysis tools to make sure the index designing, hierarchy relations and the important degree in the configuration process of the employee turnover risk evaluation system model.

- Case-based reasoning (CBR) method can meet the need of evaluation system model through requirement description, case extraction and proposal revision, etc.

- Reality research method made use of questionnaire survey to collect data, and then make out the employee turnover risk factors and their functional mechanism path model by data analyzing.

- Manual configuration method took the customer-driving way to configure the evaluation system model through certain human-computer interaction [9]. The above three methods all need the manual configuration method modulating to satisfy the requirement of evaluation. 


\subsection{Confirmation Stage of Evaluation System Model}

The confirmation stage of employee turnover risk evaluation system model was to check and confirm the configured system model completely. It began from the bottom layer of risk factors, and then checked them subsequently. Each layer factors need to pass three kinds of confirm: integrity confirmation, feasibility confirmation and compatibility confirmation.

- Integrity confirmation: to confirm if the same group index factors can satisfy the need of expressing their up-degree index completely.

- Feasibility confirmation: to check if the index factors have the possibility of operation and if the basic information they need can be found in the relevant enterprises.

- Compatibility confirmation: to confirm the interrelation, restriction and confliction degree between the same group index factors. If the factors were more related, use one representative index instead, and if the two kinds of index factors were conflicting, discriminate them by different important degree and weight power.

\subsection{CBR Technique in Employee Turnover Risk Identification}

Case-Based Reasoning (CBR) is a kind of imperative knowledge management method. CBR technique provides a more ideal and feasible intelligence method for risk identification process. CBR bases on examples or experiences reasoning, providing an elicitation thinking space for question answers in the process of risk identification. Elicitation method knowledge express, retrieval and matching of cases can obtain the question answers rapidly and accurately [10]. Meanwhile, because of the case express, construction of case warehouse can stand on the time space and geography space of questions, it satisfies the demand of risk identification process completely.

The application of CBR technique in employee turnover risk identification mainly involves knowledge expressing, case organizing and management, and case extracting methods.

Case knowledge expressing is to realize the organically combination of case relevant information. Object-oriented knowledge expressing allows decompose complicated objects into some single objects, it was used into the process of identifying employee turnover risk. Employee turnover risk identification objects include source of risk, risk hazard, peril and exposure of loss.

Relation database was used to store case information of employee turnover risk identification. In the case warehouse, employee turnover risk source object, employee turnover risk hazard object, employee turnover risk peril object and employee turnover risk loss object were corresponded with different table structure respectively. Among which, table structure corresponded to employee turnover risk identification cases is the master table. Table structures corresponded to each sub-objects were connected with master table through their index information-- sub-object case codes, this organizing method can make a sub-object case serve several risk identification cases, thus greatly save the space of case warehouse (See Figure 4). 


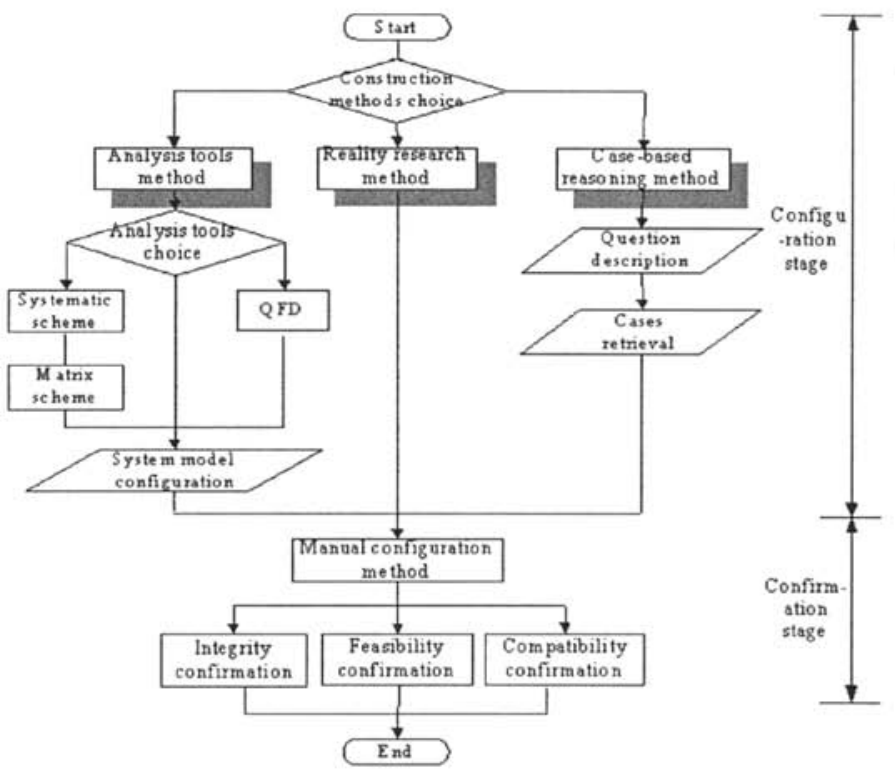

Figure 3. Designing Process Model of Employee Turnover Risk Evaluation System

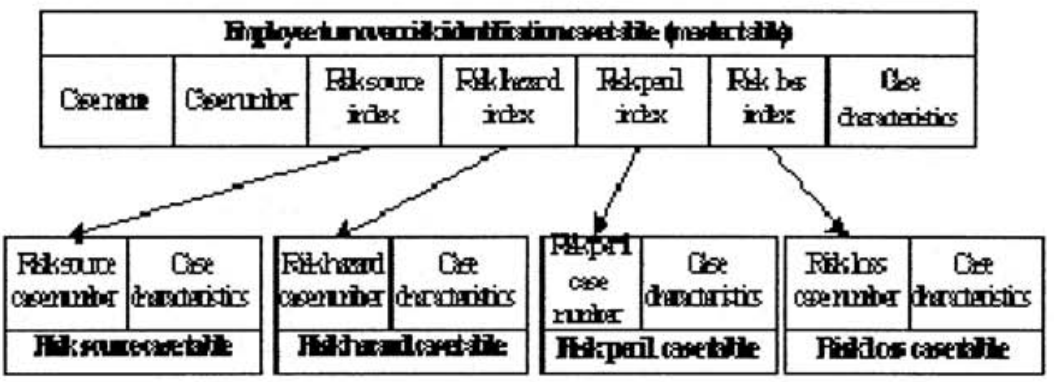

Figure 4. Case Warehouse Organizing Structure

Case extraction is a process of query and matching. According to employee turnover risk identification features, enterprise type, enterprise location, employee type, employee personal conditions were used as query conditions, and they belong to different query level; acquiring similar case collection from case warehouse through selecting corresponding query conditions, and from which the best case recommending to be used as reference case was retrieved; retrieving the best case is to draw out the most similar case or case part with solving problem characteristics from achieving similar cases. 


\section{CONCLUSIONS}

Evaluation system model designing is a key point of employee turnover risk evaluation. It is important to the validity and veracity of evaluation result, so it has significant meaning to study the designing of risk evaluation system model, the designing process and method.

This article studied the designing process and techniques of employee turnover risk evaluation system model based on analyzing the influencing factors of employee turnover risk. Combining the analysis tools and relevant technology and method, the designing process model of risk evaluation system model was put forward in this article. CBR technique was provided to be a better way in solving the problem of intelligence supporting in risk identification process, thus played an important role in the application of employee turnover risk identification system in enterprises.

Employee turnover risk evaluation system model designing and the research and application of relevant techniques and methods have important theoretical value and reality designing on the development of employee turnover risk evaluation activities in enterprises, thus can manage the employee turnover risk effectively.

\section{REFERENCES}

1. G. Bohlander and S. Snell, Managing Human Resources (Dongbei University of Finance \& Economics Press: Dalian, 2004).

2. M. Guo, J. Shi, Employee Turnover and Strategies in High-tech Enterprises, Human Resources Development. Volume 8, Number 1, pp.53-56, (2001).

3. J. Li and Y. Yu, Knowledge Worker Turnover Risk Management, Shandong Society Science. Number 3, pp.35-37, (2003).

4. B. Liao and X. Ji, Knowledge worker turnover risk management, Contemporary Management Science. Number 12, pp.26-27, (2003).

5. D. $\mathrm{Li}$, The international new tendency of enterprise risk management- the entirety risk management, Contemporary Finance and Economics. Number 11, pp.79-81, (2003).

6. S.S Randall, M.M. Shannon, O.M. Joanna, and A.M. Smith, Employee turnover: a neural network solution, Computers \& Operations Research. Volume 32, pp.2635-2651, (2005).

7. C. Jiang and S. Zhao, Features, reasons and strategies of Knowledge Worker Turnover, China Soft Science. Number 2, pp.85-88, (2001).

8. J.L. Price, Introduction to the Special Issue on Employee Turnover, Human Resource Management Review. Volume 9, pp.387-395, (1999).

9. L.K. Chan and M.L. Wu, Priorizing the Technical Measures in Quality Function Deployment, Quality Engineering. Volume 3, pp.467-479, (1998).

10. I.D. Waston (Ed.), Progress in Case-Based Reasoning (Spring: Germany, 1995). 